удК 347.963

А. А. Протасевич

Байкальский государственный университет, г. Иркутск, Российская Федерация

А. В. Гуменюк Байкальский государственный университет, 2. Иркутск, Российская Федерация

В. Г. Пирва

Байкальский государственный университет, 2. Иркутск, Российская Федерация

\title{
ПРОКУРОРСКИЙ НАДЗОР \\ ЗА ОРГАНАМИ, ОСУЩЕСТВЛЯЮЩИМИ ДОЗНАНИЕ
}

АНнотАция. В настоящей статье приводятся различные подходы ученых к определению понятия «Прокурорского надзора» как отрасли права. Определяется предмет и сущность прокурорского надзора за органами, осуществляющими дознание. Обращается внимание на различное законодательное определение отрасли прокурорского надзора в различных нормативных правовых актах. В данной статье отмечаются актуальные вопросы деятельности прокуратуры при осуществлении данного надзора. Ставиться вопрос о целесообразности широких полномочий сотрудника прокуратуры Российской Федерации на стадии досудебного производства. Называется нормативно-правовая база, регулирующая деятельность сотрудников прокуратуры. Упоминается полномочия прокурора при поступлении обвинительного акта. Процессуальные нарушения дознавателя при составлении обвинительного акта и обвинительного постановления. Процедура признание постановления дознавателя незаконным и необоснованным. Определяются процессуальные нарушения дознавателя при прекращении уголовного дела, а также полномочия прокурора Российской Федерации при выявлении вышеуказанных нарушений.

кЛЮчЕВЫЕ СЛОВА. Прокурорский надзор; предмет прокурорского надзора; прокурорский надзор за органами, осуществляющие дознание; полномочия прокурора Российской Федерации; обвинительный акт; обвинительное постановление; прекращение уголовного дела.

ИНФОРМАЦИЯ О СТАТЬЕ. Дата поступления 26 июля 2017 г.; дата принятия к печати 11 октября 2017 г.; дата онлайн-размещения 25 октября 2017 г.

A. A. Protasevich Baikal State University, Irkutsk, Russian Federation

A. V. Gumenyuk Baikal State University, Irkutsk, Russian Federation

V. G. Pirwa

Baikal State University, Irkutsk, Russian Federation

\section{PROSECUTOR'S SUPERVISION OF AUTHORITIES CONDUCTING INVESTIGATIONS}

ABSTRACT. The article presents various approaches of scientists to definition of the concept «Prosecutor's supervision» as a branch of law. It determines the subject and the essence of prosecutor's supervision over the bodies conducting the inquiry. Attention is drawn to the various legislative definition of the Prosecutor's supervision sector in various legal acts. The article notes topical issues of the prosecutor's office activities in exercising this supervision. It poses the question of reasonability of broad powers of a member of the prosecutor's office of the Russian Federation at the pre-trial stage. It designates the normative and legal base that regulates activities of prosecutor'

(C) А. А. Протасевич, А. В. Гуменюк, В. Г. Пирва, 2017

\section{Baikal Research Journal}


office members. The article mentions the prosecutor's powers upon admission of an indictment, procedural violations of the investigator in preparing the indictment and the accusatory act, as well as the procedure of recognition of the investigator's decision to be unlawful and groundless. The article identifies procedural violations of the investigator at termination of the criminal case and also the powers of the Prosecutor General of the Russian Federation in revealing the above-mentioned violations.

KEYWORDS. Prosecutor's supervision; subject of prosecutor's supervision; prosecutorial supervision of authorities conducting investigations; powers of the Prosecutor General of the Russian Federation; indictment; accusatory act; termination of criminal case. ARTICLE INFO. Received July 26, 2017; accepted October 11, 2017; available online October 25, 2017.

11.01.2011 г. в столице России г. Москве на Всероссийском совещании прокуроров В. В. Путин акцентировал свое внимание на следующем, что «Работа прокуратуры - это авторитет государственной власти, на которой лежит обязанность обеспечивать безопасные условия жизни каждому гражданину России». [1, с. 342]

В статье 1 Федерального закона Российской Федерации от 17.01.1992 года № 2202-1: «О прокуратуре Российской Федерации» прокуратура определяется как единая федеральная централизованная система органов, осуществляющих от имени Российской Федерации надзор за соблюдением Конституции РФ и исполнением законов, действующих на территории РФ.

Д. А. Медведев приобщил к числу самых важных задач, которые стоят перед прокурорским надзором, усиление надзора за соблюдением законов органами, осуществляющими оперативно-розыскную деятельность, дознание и предварительное следствие ${ }^{1}$.

Понятие «прокурорский надзор» рассматривается в доктрине уголовно- процессуального права в двух аспектах:

1) как основная функция прокуратуры - определенный вид деятельности;

2) совокупность правовых отношений, которые складываются в ходе реализации данной деятельности.

Современное состояние уголовно - процессуального права не позволяет утверждать о существовании отдельного пласта надзорных правоотношений. В этой связи, на сегодняшний день, более правильным стоит определять прокурорский надзор как отдельный вид правоприменительной деятельности.

В качестве предмета надзора, в соответствии со ст. 29 Закона РФ «О прокуратуре Российской Федерации», являются соблюдение прав и свобод человека и гражданина, установленного порядка разрешения заявлений и сообщений о совершенных и готовящихся преступлениях, выполнение оперативно-розыскных мероприятий и проведение расследования, законность решений, принимаемых органами, осуществляющими оперативно-розыскную деятельность, дознание и предварительное следствие ${ }^{2}$.

Под понятием «предмет прокурорского надзора» понимается: 1) соблюдение законности. При этом понятие «законность» шире самого понятия «закон»; 2) исполнение законов министерствами (в том числе ведомствами и службами), организациями, должностными лицами и гражданами; 3) общественные отношения, регулирование которой направлена деятельность прокурора; 4) норма права, регламентирующая деятельность объектов надзора по направлениям его осуществления, и т.д.

\footnotetext{
${ }^{1}$ Вступительное слово Д. А. Медведева на расширенном заседании коллегии Генеральной прокуратуры России // Следователь. 2009. № 3. С. 5.

${ }^{2}$ О прокуратуре Российской Федерации : федер. закон РФ от 17.01.1992 г. № 2202-1 // Собрание законодательства РФ. 1995. № 47. Ст. 4472.
}

\section{Baikal Research Journal}


В то же время, соглашаясь с В. Н. Рябовым [2, с. 15], наиболее точным считается подход М. Н. Маршунова, в котором определяется «предмет прокурорского надзора как законность деятельности и актов поднадзорных органов, организаций и лиц применительно к отдельным направлениям надзорной деятельности» [3, с. 98].

Предметом прокурорского надзора как вид государственной деятельности является общественные отношения, на регулирование которых направлена деятельность прокурора. Эти общественные отношения связаны с исполнением законов юридическими лицами, физическими лицами и должностными лицами, кроме высших органов представительной, исполнительной власти РФ и судебных органов.

Необходимо сделать акцент на различное определение законодателя, рассматриваемой отрасли прокурорского надзора. Согласно ст. 29 ФЗ «О прокуратуре РФ» ${ }^{3}$ надзор осуществляется за исполнением законов органами предварительного следствия, а в статье 37 УПК Российской Федерации ${ }^{4}$ определяет надзор за процессуальной деятельностью органов предварительного следствия.

На наш взгляд, уголовно-процессуальное законодательство сужает предмет прокурорского надзора в данной сфере надзора, поскольку согласно приказам Генерального прокурора Российской Федерации, прокурорский надзор за деятельностью органов предварительного следствия происходит и вне уголовно-процессуальной сферы [4, с. 38$]$

Говоря, о прокурорском надзоре, нужно иметь ввиду, что надзор не только основная функция прокуратуры, но еще и системообразующая. Другие направления деятельности прокуратуры определены существованием прокурорского надзора и обеспечивают его эффективность [5, с. 34]

Осуществляя проверку в порядке надзора, прокурор имеет право требовать, находящиеся в производстве органов дознания, разрешенные заявления и сообщения о преступлениях, книги и журналы их регистрации и учета, переписку и прочие документы, связанные с работой по заявлениям и сообщениям о преступлениях для ознакомления.

В соответствии с п. 1.3. Приказа Генеральной прокуратуры РФ № 277 от 05.09.2011 г. «Об организации прокурорского надзора за исполнением законов при приеме, регистрации и разрешении сообщений о преступлениях в органах дознания и предварительного следствия», для проверки полноты регистрации сообщений о преступлениях и выявления нарушений, связанных с укрытием преступлений от регистрации и учета, прокуратура ежемесячно производит сверку регистрационно-учетных данных органов дознания с учетной документацией медицинских учреждениях, страховых компаний, государственных контролирующих, надзорных и контрольно-ревизионных органов, а также других учреждений.

Мерами выражения прокурорского реагирования на выявленные нарушения закона при производстве следственных и иных процессуальных действий являются акты прокурорского надзора, представляющие собой исходящие от прокурора указания, представления и иные принятые им решения в надлежащей письменной форме.

Некоторые авторы ставят под сомнение целесообразность весьма широких полномочий прокурора на стадии досудебного производства в отношении подразделений дознания. При этом говорится, что от санкционирования прокурором ряда действий дознавателей никак не зависит качество расследования уголовных дел. С учетом этого и предлагается избавить дознавателей от излишней процессуальной зависимости от прокурора [6, с. 147].

\footnotetext{
${ }^{3}$ О прокуратуре Российской Федерации : федер. закон РФ от 17.01.1992 г. № 2202-1 // Собрание законодательства РФ. 1995. № 47. Ст. 4472.

${ }^{4}$ Уголовно-процессуальный кодекс Российской Федерации : федер. закон от 18.12.2001 г. № 174Ф3 : (ред. от 12.07.2017) // Собрание законодательства РФ. 2001. № 52, ч. 1. Ст. 4921.
}

\section{Baikal Research Journal}

электронный научный журнал Байкальского государственного университета 
В части 2 статьи 1 Федерального закона Российской Федерации от 17.01.1992 г. № 2202-1: «О прокуратуре Российской Федерации» определяются отдельные виды надзора прокуратуры Российской Федерации, а надзор за исполнением законов органами, осуществляющими оперативно-розыскную деятельность, дознание и предварительное следствие - в самостоятельную отрасль надзора.

Считается, что понятие «надзор за исполнением законов органами, осуществляющими дознание» немного шире понятия «прокурорский надзор за процессуальной деятельностью органов дознания».

Сущность прокурорского надзора за исполнением законов органами дознания характеризуют следующими признаками:

1. Реальное обеспечение формами и средствами прокурорского надзора, соблюдение органами дознания конституционных прав.

2. Обеспечение точного и безусловного исполнения органами дознания требований закона по принятию мер предупреждения и пресечения совершенных и готовящихся преступлений, выявлению и привлечению к ответственности лиц, виновных в совершении преступных посягательств.

3. Обеспечение процессуального руководства за проведением дознания по конкретным уголовным делам.

Генеральный прокурор РФ придает большое значение защите прав и свобод человека и гражданина, в связи с этим издал ряд Приказов.

Приказ представляет собой «официальное распоряжение руководителя, начальника подчиненным» [7, с. 54] или «официальное указание, подлежащее неукоснительному исполнению» [8, с. 398].

Приказы Генерального прокурора РФ относятся к категории ведомственных нормативных актов. Они основываются на положениях Конституции РФ, Федерального закона «О прокуратуре РФ» и других законов, международных договоров РФ. Приказы Генерального прокурора РФ издаются в целях надлежащего исполнения вышесказанных нормативных правовых актов по ключевым, основополагающим вопросам организации и порядка деятельности прокуратуры.

Сущность данной отрасли прокурорского надзора характеризуют и стоящие перед ней задачи. Они поставлены нормами Федеральным законом «О прокуратуре РФ», УПК и иных федеральных законов, которые регламентируют деятельность правоохранительных органов, а также указаний и приказов Генерального прокурора РФ.

В статье 40 Уголовного-процессуального кодекса Российской Федерации при определении круга органов дознания относятся руководители определенных учреждений (начальников, командиров), а также государственные органы (органы внутренних дел РФ, иных органов исполнительной власти, наделенные полномочиями по осуществлению ОРД в соответствии с федеральным законом) без указания, какие должностные лица правомочны вести расследование.

В соответствии со ст. 41 УПК РФ дознаватель вправе по находящимся в его производстве делам самостоятельно проводить следственные и иные процессуальные действия и принимать процессуальные решения, за исключением случаев, когда в соответствии с УПК РФ на это требуется согласие начальника органа дознания, согласие прокурора и (или) судебное решение, а также осуществлять иные полномочия, предусмотренные УПК РФ [9, с. 40].

На наш взгляд, непосредственное изучение материалов уголовного дела, представляет собой наиболее действенную и әффективную форму надзора. Вышеуказанное ознакомление прокурор производит по письменному мотивированному запросу, который направляется следователю или дознавателю. В начале изучения уголовного дела, прокурор должен обращать внимание на обоснованность и за-

\section{Baikal Research Journal}

электронный научный журнал Байкальского государственного университета 
конность задержания лица, который подозревается в совершение преступления, а также, чтобы задержание было осуществлено в точном соответствии с требованиями статьи 91 и 92 УПК РФ. Необходимо, также обращать внимание на процессуальное оформление и сроки такого задержания.

В соответствии с пп. «с» п. 1 ст. 5 Европейской конвенции «О защите прав человека и основных свобод» законный арест или задержание лица допустимы только в том случае, если в порядке, установленном законом, они произведены с тем, чтобы лицо предстало перед судебным органом по обоснованному подозрению в совершении правонарушения или в случае, когда имеются основания полагать, что необходимо предотвратить совершение им правонарушения или помешать ему скрыться после его совершения. Суждения лица или органа, принимающего решение о применении меры пресечения, должны основываться не на интуиции, а на базе конкретных доказательств, полученных в порядке, установленном уголовно-процессуальным законодательством, с соблюдением процессуальной формы их получения, закрепления, оценки и применения [10, с. 2].

Окончание предварительного расследования в форме дознания может быть завершено с вынесения обвинительного акта, обвинительного постановления, либо постановления о прекращении уголовного дела [11, с. 297].

Если дознание по уголовному делу завершается составлением обвинительного акта, то здесь могут допускаться следующие нарушения:

- неверная квалификация деяния;

- неправильная формулировка обвинения;

- отсутствие данных о потерпевшем и размере причиненного ему вреда;

- не указано о наличии отягчающих или смягчающих обстоятельств. При поступлении обвинительного акта прокурор уполномочен:

1) утвердить обвинительный акт по уголовному делу и направить его в суд, в соответствии с п. 14 ч. 2 ст. 37 УПК РФ. Проверка законности обвинительного акта должна быть осуществлена в срок не более 2-х суток, в течение которых прокурор проверяет: соблюдение требований уголовно-процессуальных норм, допустимость доказательств, нашли ли свое подтверждение выводы, указанные в обвинительном акте в собранных доказательствах.

При этом прокурор в ходе изучения, находящегося в проверке уголовного дела, обязан придерживаться принципа презумпции невиновности, в соответствии ст. 14 УПК РФ. В обязанность прокурора входит проверка полноты и всесторонности проведенного расследования, доказанности фактов, изложенных в обвинении, правильной квалификации совершенного деяния, в соответствии с нормами материального права. Колоссальное значение имеет, чтобы в процессе дознания не нарушались права участников, предусмотренные и гарантированные законом, при ознакомлении с материалами уголовного дела, и в частности, соответствия обвинительного акта требованиям, предусмотренным ст. 225 УПК РФ.

При утверждении обвинительного акта прокурор своим постановлением вправе переквалифицировать обвинение на менее тяжкое.

В соответствии с приказом Генеральной прокуратуры РФ от 06.09.2007 г. № 137 прокурор уполномочен давать указания по корректировке доказательственной базы, которую в ходе поддержки государственного обвинения, придется представлять в суде. Выявив недопустимые доказательства, прокурор вправе вынести мотивированное постановление об их исключении из обвинительного акта.

В случаях, когда вместе с поступившим обвинительным актом должен решиться вопрос о мере пресечения, прокурор вправе изменять или отменять ее, если сроки содержания под стражей истекли, в соответствии п. 12 и 14 приказа Генеральной прокуратуры РФ № 137 от 06.09.2007 г., который устанавливает

\section{Baikal Research Journal}

электронный научный журнал Байкальского государственного университета 
обязанность прокуроров «обеспечивать надлежащий прокурорский надзор за неукоснительным соблюдением органами дознания требований уголовно-процессуального законодательства при применении процессуальных мер принуждения и пресечения», а «также своевременно принимать меры к пресечению необоснованного и незаконного применения к подозреваемым и обвиняемым мер процессуального принуждения в ходе предварительного расследования».

«Прокурор должен возбуждать перед судом ходатайство о продлении срока содержания под стражей или домашнего ареста, при наличии законных оснований, если ко времени направления дела в суд, срок вышеуказанных мер пресечения является недостаточным для выполнения требований суда» ${ }^{5}$.

2) вернуть поступившее дознавателю дело для:

- осуществления дополнительной проверки, при этом срок дознания может увеличиваться, но не более чем на 10 суток;

- корректировки акта, при несоответствии его положениям ст. 225 УПК РФ предоставляя срок не более 3 суток.

Необходимо возвращать уголовные дела на дополнительную проверку при выявлении неполноты произведенного дознания, а также нарушения уголовно-процессуального, уголовного законодательства органами дознания, недостаточной доказательственной базой, для подтверждения виновности обвиняемого, а также признание имеющихся доказательств недопустимыми ст. 75 УПК РФ.

После того, как прокурор изучил уголовное дело, может прийти к мнению, что выводы дознавателя об установлении события преступления и о виновности обвиняемого не нашли своего отражения в представленных доказательствах, на которые имеется ссылка в обвинительном акте. Прокурор обязан уделять особое внимание доводам защиты, пояснениям обвиняемого, доказывающего свою невиновность, прошедшим проверку в ходе расследования и отраженными в обвинительном акте, и имеются ли объективные и допустимые доказательства, устанавливающие несостоятельность объяснений обвиняемого, так как, материалы расследования только тогда могут быть признаны достоверными и несомненными, когда собранные по делу доказательства опровергают версии, исключающие виновность обвиняемого, отрицающего свою вину $[12$, с. 4$]$.

Если имеются основания для возвращения уголовного дела, прокурор имеет право вынести мотивированное постановление, с обязательным указанием нарушений, которые были допущены при расследовании, необходимости их устранения, а также дополнительные обстоятельства, которые должны быть установлены, какие дополнительные следственные действия требуется произвести и какие выяснить обстоятельства.

3) Принимаются решения «о прекращении уголовного дела по основаниям, предусмотренным статьями 24-28 УПК РФ» (п. 3 ч. 1 ст. 226 УПК РФ) уголовно-процессуальный закон предусматривает закрытый перечень оснований для прекращения уголовных дел.

Основанием для прекращения уголовного дела должно быть то, которое наиболее полно подходит для конкретного случая и будет единственно правильным $[13$, c. 63$]$.

4) Направляются материалы дела в следственные органы в соответствии с п. 4 ч. 1 ст. 226 УПК РФ. Данное полномочие реализуется прокурором в виде письменного указания и только в том случае, когда в срок, предоставляемый уголовно-процессуальным законодательством для дознания, не представляется возможным в полном объеме подготовить дело для судебного разбирательства.

${ }^{5}$ Уголовно-процессуальный кодекс Российской Федерации : федер. закон от 18.12.2001 г. № 174ФЗ : (ред. от 12.07.2017) // Собрание законодательства РФ. 2001. № 52, ч. 1. Ст. 4921.

\section{Baikal Research Journal}

электронный научный журнал Байкальского государственного университета 
Если дознание проводилось в сокращенной форме, то по окончании предварительного расследования к прокурору поступает обвинительное постановление.

В данном случае полномочия прокурора аналогичны полномочиям прокурора в отношении проверки обвинительного акта. Различия состоят в ограничении срока принятия решения тремя сутками, и вправе направить дело дознавателю для производства в общем порядке.

При проверке законности прокурором дополнительно проверяется, имелись ли законные основания для проведения дознания в сокращенной форме, наличие обстоятельств, исключающих дознание в такой форме и соблюдены ли все необходимые требования для этой формы расследования, а также, не нарушены ли сроки вынесения обвинительного постановления.

Предварительное расследование может быть окончено вынесением дознавателем постановления о прекращении уголовного дела в порядке ст. 212, 213 УПК РФ. Прокурор может как утвердить данное постановление в силу п. 13 ч. 2 ст. 37 УПК РФ, так и отменить его. Для проверки принятого решения дознавателя и реализации данных полномочий прокурору требуется направить запрос на предоставление материалов уголовного дела.

Дознаватель принимает решение о прекращение уголовного дела, которое находится у него производстве, тем самым выносит постановление в порядке ст. 212, 213 УПК РФ, в связи с этим прокурор либо утверждает в порядке п. 13 ч. 2 ст. 37 УПК РФ, либо отменяет данное постановление.

Постановление о прекращение уголовного дела - это решение дознавателя, в производстве которого находится данное уголовное дело, об окончании процессуальной деятельности и завершение уголовного процесса, без передачи его в суд $[14$, c. 219].

Вместе с прекращением уголовного дела, прекращению подлежит и уголовное преследование. Дело может быть прекращено по реабилитирующим и не реабилитирующим основаниям. К реабилитирующим относятся: отсутствие события преступления, отсутствие состава преступления и т.д.; к не реабилитирующим истечение сроков уголовного преследования; смерть подозреваемого; примирение сторон и др.

При прекращении уголовного дела, чаще всего, допускаются нарушения в двух формах, которые влекут за собой его незаконность [15, с. 111]:

1) Прекращение уголовного дела, без должных на то оснований;

2) Прекращение уголовного дела с нарушением оснований прекращения. Как правило, это прекращение по не реабилитирующим основаниям, в случае, недоказанности вины.

Право прокурора на отмену незаконного и необоснованного постановления дознавателя о прекращении уголовного дела закреплено в п. 6 ч. 2 ст. 37 в порядке, определяемом ст. 214 УПК РФ.

В рамках своих полномочий прокурор проверяет наличие таких оснований для прекращения уголовного дела, предусмотренных не только уголовно-процессуальным законодательством, но и материальным правом:

- полноту и объективность предварительного расследования;

- соблюдены ли права потерпевших;

- приняты ли дознавателем все меры к установлению лица, подлежащего привлечению в качестве обвиняемого;

- все ли следственные действия выполнены, без которых не может быть принято решение об окончании предварительного расследования;

- правильно ли квалифицировано основание прекращения производства по уголовному делу. В целях восстановления прав лица, привлекаемого в качестве

\section{Baikal Research Journal}

электронный научный журнал Байкальского государственного университета 
подозреваемого, приняты ли меры по реабилитации лица, также наличие согласий обвиняемого, потерпевшего, когда этого требует закон;

- направлены ли копии постановления лицу, в отношении которого принято постановление и потерпевшему;

- при рассмотрении заявлений и жалоб граждан о незаконности прекращения уголовного дела прокурор должен особое внимание обратить на проверку всех доводов заявителей. ${ }^{6}$

Если прокурор признает постановление дознавателя необоснованным и незаконным, то своим решением его отменяет и возобновляет производство. Необходимо отметить, что законодатель не прописывает требования от прокурора письменного мотивированного постановления, а также не устанавливает срок для принятия решения. Тогда как в отношении отмены аналогичных постановлений органов следствия, данный срок устанавливается в пределах 14 суток, а также, обязательность наличие письменного мотивированного постановления в соответствии с ч. 1 ст. 214 УПК РФ.

Современные тенденции России к демократическим преобразования, происходящие в нашей стране, провозглашение приоритета личности создают предпосылки для повышения роли прокуратуры как федерального централизованного надзорного органа по укреплению законности, справедливости и правопорядка в стране. Как уже было сказано, прокурорский надзор за предварительным расследованием занимает ведущее место среди иных направлений прокурорского надзора, потому что именно на данной стадии наиболее остро затрагиваются гарантированные Конституцией РФ права и интересы человека.

В части касающегося полномочий прокурора за соблюдением законов органами, осуществляющими дознание можно сделать следующие выводы, что эффективность прокурорского надзора может быть достигнута только путем тщательной и всесторонней проверки соблюдения и исполнения, установленного уголовно процессуальным законом, межведомственными и ведомственными нормативными правовыми актами норм и требований. При этом прокурор обязан проводить проверки с целью выявления нарушений закона и принимать соответствующие меры к их устранению, пресечению и предупреждению в дальнейшем.

Прокурор, осуществляя свои полномочия по ознакомлению материалов предварительного расследования, обобщению практики по расследованию преступлений, рассмотрению жалоб граждан РФ на действия должностных лиц и государственных органов, осуществляющих уголовно-процессуальную деятельность, а так же лиц, которые координируют деятельность правоохранительных органов при осуществлении деятельности по расследованию преступлений, обязан выявлять нарушения законодательства, допущенные следователем и дознавателем. Для того чтобы прокурор убедился, что права всех участников уголовного процесса не нарушаются и все доказательства соответствуют уголовно-процессуальному законодательству, он имеет право ознакомиться с материалами уголовного дела, которые находятся в производстве у дознавателя или следователя.

\section{Список использованной литературы}

1. Вершинин А. Д. Прокуратура на современном этапе / А. Д. Вершинин. - Самара : Изд-во Самарского ун-та. $-2006 .-348$ с.

2. Рябов В. Н. Прокурорский надзор за исполнением законов в оперативно-розыскной деятельности криминальной милиции : моногр. / В. Н. Рябов. - Хабаровск : ДВЮИ МВД России, 2001. - 245 с.

${ }^{6}$ Об основных направлениях работы с кадрами в органах и учреждениях прокуратуры РФ : приказ Генпрокуратуры России от 20.02.2013 г. № 80 // Законность. 2013. № 5. С. 68-72.

\section{Baikal Research Journal}

электронный научный журнал Байкальского государственного университета 
3. Маршунов М. Н. Прокурорско-надзорное право. Проблемы правового регулирования / М. Н. Маршунов. - СПб. : Изд-во СПб. ун-та, 1991. - 128 с.

4. Винокуров Ю. Е. Прокурорский надзор : учебник / Ю. Е. Винокуров. - М. : Высшее образование, 2007. - 736 с.

5. Григорьев В. Н. Процессуальная регламентация предварительного расследования в результате реформы 2007 г. / В. Н. Григорьев, В. Н. Калинин, А. В. Победкин // Государство и право. - 2008. - № 6. - С. 48-58.

6. Киреева Е. А. Проблемы отсутствия процессуальной самостоятельности дознавателей / Е. А. Киреева // Проблемы управления органами расследования преступлений в связи с изменением уголовно-процессуального законодательства : материалы межвуз. науч.-практ. конф. В 2-х ч. - М. : Академия управления МВД России, 2008. - Ч. 1. - С. 147-148.

7. Бессарабов В. Г. Защита российской прокуратурой прав и свобод человека и гражданина / В. Г. Бессарабов, К. А. Кашаев. - М. : Городец, 2007. - 464 с.

8. Ожегов С. И. Толковый словарь русского языка / С. И. Ожегов, Н. Ю Шведова. М. : ИТИ Технологии, 2003. - 944 с.

9. Комментарий последних изменений уголовно-процессуального кодекса Российской Федерации и Федерального закона «О прокуратуре РФ» / А. С. Александров [и др.]. - М. : Юрайт, 2008. - 480 с.

10. Мельников В. Ю. Применение мер пресечения в отношении подозреваемых и обвиняемых / В. Ю. Мельников // Российский судья. - 2007. - № 7. - С. 29-34.

11. Сухарев А. Я. Прокурорский надзор : учебник / А. Я. Сухарев. - М. : НОРМА, 2003. - 297c.

12. Назаров С. Н. Соотношение форм реализации права и функции надзора прокуратуры / С. Н. Назаров // История государства и права. - 2008. - № 6. - С. 3-5.

13. Соловьев А. Б. Прокурор в досудебных стадиях уголовного процесса России / А. Б. Соловьев, М. Е. Токарева, Н. В. Буланова - М. : Юрлитинформ, 2006. - 176 с.

14. Пикалов И. А. Уголовный процесс Российской Федерации (краткий курс) : учеб. пособие / И. А. Пикалов. - Курган : Изд-во Курганского гос. ун-та, 2005. - 318 с.

15. Шимановский В. В. Обеспечение законности и прокурорский надзор при прекращении уголовного дела на предварительном следствие и дознании : учеб. пособие / В. В. Шимановский. - СПб. : ИПК прок. следств. работников, 1996. - 53 с.

\section{References}

1. Vershinin A. D. Prokuratura na sovremennom etape [Prosecutor's office at current stage]. Samara University Publ., 2006. 348 p.

2. Ryabov V. N. Prokurorskiiy nadzor za ispolneniyem zakonov $v$ operativno-rozysknoy deyatelnosti kriminalnoy militsii [Prosecutor's supervision of law implementation in operational search activities of criminal militia]. Khabarovsk Institute of the MIA of Russia Publ., 2001. 245 p.

3. Marshunov M. N. Prokurorsko-nadzornoe pravo. Problemy pravovogo regulirovaniya [Prosecutorial and supervisional law. Problems of legal regulation]. Saint Peterburgsky University Publ., 1991. 128 p.

4. Vinokurov Yu. E. Prokurorskii nadzor [Prosecutor's supervision]. Moscow, Vysshee obrazovanie Publ., 2007. 736 p.

5. Grigor'ev V. N., Kalinin V. N., Pobedkin A. V. Procedural regulation of preliminary investigation as a result of 2007 reform. Gosudarstvo $i$ pravo $=$ State and Law, 2008. no. 6, pp. 48-58. (In Russian).

6. Kireeva E. A. Problems of absence of investigators'procedural independence. Problemy upravleniya organami rassledovaniya prestuplenii $v$ svyazi s izmeneniem ugolovno-protsessual'nogo zakonodatel'stva. Materialy mezhvuz. nauch.praktich. konf. V 2-kh ch. [Problems of managing of criminal investigation bodies in the context of changes in criminal and procedural legislation. Materials of Inter-University Science and Practice Conference. In two Parts.]. Moscow, Management Academy of MIA Russia Publ., 2008, vol. 1, pp. 147-148. (In Russian).

7. Bessarabov V. G., Kashaev K. A. Zashchita rossiiskoi prokuraturoi prav $i$ svobod cheloveka $i$ grazhdanina Defense by Prosecutor's Office of human and civil rights and liberties]. Moscow, Gorodets Publ., 2007. 464 p.

\section{Baikal Research Journal}

электронный научный журнал Байкальского государственного университета 
8. Ozhegov S. I. Tolkovyi slovar' russkogo yazyka [Explanatory Dictionary of the Russian Language]. Moscow, ITI Tekhnologii Publ., 2003. 944 p.

9. Aleksandrov A. S., Korolev G. N., Polyakov M. P. Kommentarii poslednikh izmenenii ugolovno-protsessual'nogo kodeksa Rossiiskoi Federatsii i Federal'nogo zakona «O prokurature $R F$ » [Comment on recent changes in Criminal and Procedural Code of the Russian Federation and Federal Law «On Prosecutor's Office of the Russian Federation»]. Moscow, Yurait Publ., 2008. $480 \mathrm{p}$.

10. Mel'nikov V. Yu. Use of preventive measures in regard of the suspect and accused. Rossiiskii sud'ya = Russian Judge, 2007, no. 7, pp. 29-34. (In Russian).

11. Sukharev A. Ya. Prokurorskii nadzor [Prosecutor's supervision]. Moscow, NORMA Publ., 2003. 297 p.

12. Nazarov S. N. Correlation of forms of law implementation and Prosecutor's Office functions. Istoriya gosudarstva i prava $=$ History of State and Law, 2008, no. 6, pp. 3-5. (In Russian).

13. Solov'ev A. B., Tokareva M. E., Bulanova N. V. Prokuror $v$ dosudebnykh stadiyakh ugolovnogo protsessa Rossii [Prosecutor at pre-trial stages of Russia's criminal procedure]. Moscow, Yurlitinform Publ., 2006. $176 \mathrm{p}$.

14. Pikalov I. A. Ugolovnyi protsess Rossiiskoi Federatsii [Criminal Procedure in Russian Federation]. Kurgan state University Publ., 2005. 318 p.

15. Shimanovskiĩ V. V. Obespechenie zakonnosti $i$ prokurorskiĩ nadzor pri prekrashchenii ugolovnogo dela na predvaritel'nom sledstvie i doznanii [Provision of legalism and prosecutor's supervision in ceasing a criminal case at preliminary stage of investigation and interrogation]. Saint Petersburg, IPK prosecutorial and investigative officials Publ., 1996. 53 p.

\section{Информация об авторе}

Протасевич Александр Алексеевич - директор Юридического института БГУ, заведующий кафедрой криминалистики, судебных экспертиз и юридической психологии, доктор юридических наук, профессор, заслуженный юрист Российской Федкрации, Байкальский государственный университет, 664003, г. Иркутск, ул. Ленина, 11, e-mail: ProtasevichAA@bgu.ru.

Гуленюк Анна Владилировна - ассистент кафедры криминалистики, судебных экспертиз и юридической психологии, Байкальский государственный университет, 664003, г. Иркутск, ул. Ленина, 11, e-mail: Anya4710@yandex.ru.

Пирва Виктория Геннадьевна - бакалавр юриспруденции, Байкальский государственный университет, 664003, г. Иркутск, ул. Ленина, 11, e-mail: vpirva95@mail.ru.

\section{Authors}

Alexandr A. Protasevitch - Doctor habil in Law, Professor, Director of Legal Institute of Baikal State University, head Chair of Criminalistics, Judicial Examinations and Legal Psychology, Honored Lawyer of the Russian Federation, Baikal State University,11 Lenin St., 664003, Irkutsk; e-mail: ProtasevichAA@bgu.ru.

Anna V. Gumenyuk - Assistant Lecturer, Chair of Criminalistics, Forensic Expertise and Legal Psychology, Baikal State University, 11 Lenin St., 664003, Irkutsk; e-mail: Anya4710@ yandex.ru.

Victoria G. Pirwa - Bachelor of Law, Baikal State University, 11 Lenin St., 664003, Irkutsk; e-mail: vpirva95@mail.ru.

\section{Для цитирования}

Протасевич А. А. Прокурорский надзор за органами, осуществляющими дознание / А. А. Протасевич, А. В. Гуменюк, В. Г. Пирва // Baikal Research Journal. — 2017. T. 8, № 3. - DOI: 10.17150/2411-6262.2017.8(3).17.

\section{For Citation}

Protasevich A. A., Gumenyuk A. V., Pirwa V. G. Prosecutorial supervision of authorities conducting an investigation. Baikal Research Journal, 2017, vol. 8, no. 3. DOI: 10.17150/24116262.2017.8(3).17. (In Russian).

\section{Baikal Research Journal}

